\title{
Meaning in the Miscellany of a Cultural Domain
}

\author{
Souleles, Daniel
}

Document Version

Accepted author manuscript

Published in:

Field Methods

DOI:

$10.1177 / 1525822 \times 18781822$

Publication date:

2018

License

Unspecified

Citation for published version (APA):

Souleles, D. (2018). Meaning in the Miscellany of a Cultural Domain. Field Methods, 30(4), 345-356.

https://doi.org/10.1177/1525822X18781822

Link to publication in CBS Research Portal

\section{General rights}

Copyright and moral rights for the publications made accessible in the public portal are retained by the authors and/or other copyright owners and it is a condition of accessing publications that users recognise and abide by the legal requirements associated with these rights.

Take down policy

If you believe that this document breaches copyright please contact us (research.lib@cbs.dk) providing details, and we will remove access to the work immediately and investigate your claim. 


\section{Meaning in the Miscellany of a Cultural Domain Daniel Souleles}

Journal article (Accepted manuscript* )

\section{Please cite this article as:}

Souleles, 0. (2018). Meaning in the Miscellany of a Cultural Domain. Field Methods, 30(4), 345-356. DOI:

\subsection{7/1525822X18781822}

\section{0l: https://doi.org/10.1177/1525822X18781822}

Copyright @ The Author(s) २०18. Reprinted by permission of SAGE Publications.

* This version of the article has been accepted for publication and undergone full peer review but has not been through the copyediting, typesetting, pagination and proofreading process, which may lead to differences between this version and the publisher's final version AKA Version of Record.

Uploaded to CBS Research Portal: July 2019 


\section{Meaning in the Miscellany of a Cultural Domain}

\section{Daniel Souleles}

This article compares pile sort data from frequently occurring items in a cultural domain with pile sort data on infrequently occurring items in that same cultural domain. Common practice in free list analysis has a researcher discard infrequently occurring list items. This article confirms this practice, and suggests that there is an underlying structure to both frequently and infrequently occurring list items.

Free Lists, Cultural Domain Analysis, Culture Change

\section{Humans and Lists}

There has been a long concern in the social sciences with the fact that humans categorize knowledge (e.g. Bousfield and Barclay 1950, Boudfield 1953, Henley 1969). Moreover, there has been an equally longstanding recognition that cultural importance can lead categories to proliferate and become increasingly specific (Berlin, Breedlove and Raven 1966), and, contrastingly, that categories are informed by natural or prototypical categories (Rosch 1973 and Rosch et al. 1976) as well as the morphological and distributional attributes of the objects existing in the world (Boster 1988). Running through some of these and many other studies is both a concern with frequency and clustering of items (these being the empirical gateway to categorization) and the request that informants make lists.

Free listing is a common method of gathering the items in a "cultural domain" (Borgatti 1994), an area of shared, relational knowledge (e.g. Quinlan 2005, cf. Weller 2014), or a shared schematic outline of how to sort domains of knowledge. Free lists consist of asking people to list all the items they can think of in a given domain. They have been used to study a variety of topics in the social sciences, e.g.: color categories (Smith et al. 1995, Smith and Borgatti 1998), racial categories (Gravlee 2005), stereotype-based humor (Caparoso and Collins 2015), and even romantic love (de Munck and Kronenfeld 2016). Generally, a researcher gathers multiple free 
lists from people in the same culture group, aggregates those lists, and then takes the most frequently occurring items or the items occurring nearest to the top of people's lists as a heuristic for the contents of a given cultural domain (Borgatti, 1998). After gathering frequently occurring list items, the researcher discards those that occur infrequently according to the standards of inclusiveness on a given project. This article seeks to make a contribution to this larger literature by reporting on a comparison of frequently occurring and infrequently occurring items within a common cultural domain, and suggesting both a validation of common research practices (discarding infrequently occurring items is often $\mathrm{OK}$ ), and to what use we might put those often neglected infrequently occurring items (infrequently occurring list items may help us identify things coming into and going out of a cultural domain, as well as explain things that people have trouble talking about for one reason or another).

Through the methodological literature, there's been a steady attention to free lists. Robbins and Nolan (2000) observed that as people make lists they cluster items in categories. Ryan, Nolan, and Yoder (2000) have shown that free lists items can be good recursive catalysts for generating more free lists and other cultural data. Brewer (2002) says that people often don't give an exhaustive account of all the items that they know and are usually limited by memory or researcher instructions (but there are ways to ameliorate this). Schrauf and Sanchez (2010) suggest that, in a given cultural domains, age seems to have little effect in limiting or advantaging people producing free lists. And, while often an end in and of themselves, free lists can be part of a larger cycle of data gathering and analysis (Weller 2014).

Free lists often provide more information than a researcher uses. The items that come up once or twice frequently fall out of analysis (c.f. Weller and Romney 1988:16-20). This process of culling and aggregating, or "cleaning" free list data, results in leaving behind items that occur 
below a frequency cutoff, usually at the elbow of a scree or distribution plot of listed items, but can also be adjusted depending on how much variance a researcher would like to retain (Quinlan 2005:226). Sutrop suggests that "the terms that are listed only by a single informant or by very few subjects must be considered as accidental/occasional terms" (2001:264). Similarly, when comparing free lists of the same domain across different groups of people, Thompson and Zhang (2006:407) note that what similarities they find in free lists tend to go away as more lessfrequently occurring terms are included in their analysis. Furlow (2003) observes that, even intraculturally, with a highly coherent cultural domain, there can be low informant consensus about key areas of knowledge. While I won't be advancing Furlow's concern with cultural consensus, I think scrutinizing low-frequency items in a cultural domain can offer some insight as to what may be going on in a case like Furlow's where shared knowledge is variable, but the larger structure of the cultural domain is widely understood.

What I suggest is that the infrequently occurring bits of free list elicitation are not simply accidental or occasional terms. Rather, they have some systematic relationship to the larger logic of the cultural domain in which they were elicited. This hypothesis is axiomatic of a theory of culture emergent from cultural domain analysis: because culture, in this view, is a web of related knowledge, we would expect people to place even the most infrequently occurring items, and we might even expect some sort of relationship between singleton items, and frequently occurring ones. To my knowledge, though, this axiomatic hypothesis has yet to be confirmed empirically. Too, Sutrop (2001), Thompson and Zhang (2006), and Furlow (2003)'s above noted observations about low-frequency list items suggest that this axiomatic assumption is not universally shared. This paper brings one empirical case to bear demonstrating a relationship between infrequently occurring list items and their more frequently occurring counterparts in a 
cultural domain. To do this I elicited free lists on "what college students do for fun," and used item appearance frequency as my measure of salience. In turn, I conducted a pile sort analysis of free list items, using both frequently occurring and the least occurring list items concurrently in a parallel analysis. I wanted to test whether pile-sorting with low frequency list items from a cultural domain produces a similar understanding of a cultural domain's structure as a pile-sort of high-frequency list items. Ultimately, there were similar dimensional categories used to sort both common and uncommon list items.

\section{Methods and Results}

I collected free lists of things college students do for fun from 42 students in a large, general lecture class I taught in the Fall of 2016 at Brandeis University. After cleaning the free list data, I ended up with 289 discrete items, which allowed me to produce a typical scree chart. Cleaning consisted of consolidating grammatical forms (e.g. dropping gerund "-ing” endings of present participles,), as well as condensing similar ideas into one list item (e.g. "alcohol," "drink alcohol," and "drink" all became "drink").

I then generated two decks for comparative pile sort analysis—one of common items, one of one-off singleton items. The common items set had 32 items that 7 or more people listed (Figure 1). I picked a 7-item-occurence cut-off because it was where the elbow or bend in the scree chart was (Quinlan 2005:226). The list of singleton items ended up being longer (Figure 2). I took about a quarter of 193 items that only appear once via a random sample, and generated a parallel list of 50 singleton-items. Though I had no formal rationale, 50 items, or around a quarter, chosen at random, seemed to capture an acceptable representative sense of the infrequently occurring items and kept the pile sort deck to a manageable size. One further note, 
following Bernard et al. (2009), I added one item from the singleton list that only appears once in free list responses, "pranks," to the common list to see if it got sorted similarly.

Figure 1 Frequent Free List Items

Figure 2 Singleton Free List Items

After defining the content of the two domain sets, I asked a new sample of different undergraduate students do a pile sort (Weller and Romney 1988:20ff) —30 students for the common deck, and 30 for the singleton deck, for 60 students in total. Once participants completed sorting, I asked them to explain their piles.

To analyze the pile-sort data, I conducted a non-metric multidimensional scaling and then an average-distance cluster analysis, all using Borgatti’s (1992) program, anthropac. I ended up having to run the scale in three dimensions to get the stress of the visual representation below .15 (Sturrock and Rocha 2000). The analysis seemed noisy, and pockets and clusters did not seem obvious. For an X Y and Y Z scatter chart of the MDS, see Figures 3, 4, 5, and 6. Following Kruskal and Walsh (1978:40) I've plotted $\mathrm{x}$ and $\mathrm{y}$ and $\mathrm{y}$ and $\mathrm{z}$ for the common and the singleton charts to flatten out the three dimensions. Whereas in a well-defined cultural domain, you might expect tight clusters with plenty of space between them (Kruskal and Wish 1978:16, Romney and Weller 1988:19), things seemed more hazy. So, I examined the cluster analyses.

\section{Figure 3}

Figure 4

Figure 5

Figure 6

There seemed to be similar clusters: in the common cluster there was a grouping around, "party, drink, weed, drugs, hookup, and sex;" in the singleton cluster, there was a grouping 
around, "beer pong, and parties," both gesturing to the fratty side of college life. However, the canary term, "pranks," was sorted in a different way. In the singleton pile sorts, "pranks" went in a cluster with, "frat parties, and beer pong," but in the common pile sort, pranks went with, "board games, hangout, and talk with friends," not with the party pile. It should be noted too, that in the singleton clustering, there was an analogous "friend" cluster, with, "learn about people, meet new people, catch up with friends, walk with friends, dinner with friends, and chat," all clustering and with no pranks. So, though there are similar clusters forming, there may not be a straightforward relationship between where people will integrate a particular term.

In interviews about their pile sorts, most respondents mentioned the quantity of people with whom people did a particular activity, and often explicitly invoked a spectrum of size. Rather than discrete categories, this suggests a clinal relationship between various terms. This led me to conduct a property fitting (PROFIT) analysis of the multidimensional scale I generated from the pile sorts.

Fifty students (25 each for the common and singleton set) rated each item on a four-point scale, suggesting whether it was done alone or in a group (c.f. Gravlee 2005). The common PROFIT analysis produced an $r$ squared of .686 with a $p$ of .001 , meaning that about $68 \%$ of the variance in how people are sorting things college students do for fun in the common pile is explained by whether or not they understand that activity as a solo or group activity. The singleton PROFIT analysis produced an $r$ squared of .586 with a $p$ of .001 , suggesting that about 58 percent of the variance in how people are sorting the singleton pile is explained by whether or not people see the activity as a solo or joint activity. In both the common and singleton cases of, respondents were using whether or not an activity was lonely or social as a criterion for sorting 
things that college students do for fun. Moreover, they were able to make the same type of evaluation whether or not the terms were frequently occurring or singletons.

\section{Discussion}

In this case, pile-sorting with low frequency items in a cultural domain produces a similar understanding of a cultural domain's structure as pile sorts of items with a high frequency. This suggests that we are justified, in our general use of free lists and, in the normal course of cultural domain analysis, in discarding infrequently occurring list items. Since they point towards the same structure as high frequency items, we don't seem to lose much in our analysis by ignoring them. Conversely, given that we may expect people to sort low-frequency items according to the same logic as high-frequency items, there are occasions when analyzing low frequency items could help analysts. Taboo items, overly-obvious-go-without-saying items, oddly specific items, and even new or old items should fit along the more general structure and dimensions of a given cultural domain, even if most people don't put it in their free lists. Given all this, it may be of future benefit for anthropologists to take seriously infrequently occurring items. Though, should they like to understand how whether there is some direction to whether these infrequently occurring items are waxing or waning in the culture, it may require sequential free-listing over time.

\section{References}

Berlin, Brent, Dennis E. Breedlove and Peter H. Raven. 1966. "Folk Taxonomies and Biological Classification." Science: New Series 154(3746):273-275.

Bernard, H. Russell et al. 2009. "Green Cognition and behavior: A Cultural Domain Analysis." In Networks, resources and Economic Action: Ethnographic Case Studies in Honor of Harmut Lang. Greiner, Clemens, and Waltraud Kokot, Eds. Dietrich Verlag.

Borgatti, Stephen P. 1992. Anthropac 4.983/X. Harvard, MA: Analytic Technologies. 
Borgatti, Stephen P. 1994. "Cultural Domain Analysis.” Journal of Quantitative Anthropology 4:264-278.

Borgatti, Stephen, P. 1998. "Elicitation Techniques for Cultural Domain Analysis." The Ethnographer's Toolkit, Vol. 3. Shensul, J. and M. LeCompte, Eds. Walnut Creek, Altamira Press.

Boster, James S. 1988. "Natural sources of internal category structure: Typicality, familiarity, and similarity of birds." Memory \& Cognition 16(3):258-270.

Bousefield, W. A. and W.D. Barclay. 1950. "The Relationship Bewteen Order and Frequency of Occurrence of Restricted Associative Responses." Journal of Experimental Psychology 40(5):643-647.

Bousfield, W. A. 1953. "The Occurrence of Clustering in the Recall of Randomly Arranged Associates." The Journal of General Psychology 49:229-240

Brewer. Devon D. 2002. "Supplementary Interview Tehcniques to Maximize Free Listing Tasks." Field Methods 14(1):108-118.

Caparoso, Jenna T. and Christopher S Collins. 2015. "College Student Racial and ethnic stereotype-based humor as a cultural domain." Power and Education 7(2):196-223.

De Munck, Victor C. and David B. Kronenfeld. 2016. "Romantic Love in the United States: Applying Cultural Models Theory and Methods." Sage Open January-March 2016:1-17.

Furlow, Christopher. 2003. "Comparing Indicators of Knowledge within and between Cultural Domains." Field Methods 15(1):51-62.

Gravlee, Clarence C. 2005. "Ethnic Classification in Southeastern Puerto Rico: The Cultural Model of "Color." Social Forces 83(3):949-970.

Gravlee, Clarence C. et al. 2013. "Mode Effects in Free-list Elicitation: Comparing Oral, Written, and Web-based Data Collection." Social Science Computer Review 31:119-132.

Henley, Nancy M. 1969. "A Psychological Study of the Semantics of Animal Terms.” Journal of Verbal Learning and Verbal Behavior 8:176-184.

Quinlan, Marsha B. 2005. "Considerations for Collecting Freelists in the Field: Examples from Ethnobotany.” Field Methods 17:219-234.

Robbins, Michael C. and Justin M. Nolan. 2000. "A Measure of Semantic Category Clusterings in Free-Listing Tasks.” Field Methods 12(1):18-28.

Rosch, Eleanor H. 1973. "Natural Categories.” Cognitive Psychology 4:328-350. 
Rosch, Eleanor, Carolyn B. Mervis, Wayne D. Gray, David M. Johnson, and Penny BoyesBraem. 1976. "Basic Objects in Natural Categories." Cognitive Psychology 8:382-439.

Ryan, Gery W., Justin M. Nolan, and P. Stanley Yoder. 2000. "Successive Free Listing: Using Multiple Free Lists to Generate Explanatory Models.” Field Methods 12(2):83-107.

Schrauf, Robert W. and Julia Sanchez. 2010. "Age Effects and Sample Size in Free Listing." Field Methods 22(1):70-87.

Smith, Jerome J., Louanna Furbee, Kelly Maynard, Sarah Quick and Larry Ross. 1995. "Salience Counts: A Domain Analysis of English Color Terms." Journal of Linguistic Anthropology 5(2):203-216.

Smith, Jerome J. and Stephen P. Borgatti. 1998. "Salience Counts-And so Does Accuracy: Correcting and Updating a Measure for Free-List-Item Salience." Journal of Linquistic Anthropology 7(2):208-209.

Sturrock, Kenneth and Jorge Rocha. 2000. "A Multidimensional Scaling Stress Evaluation Table." Field Methods 12(1):49-60.

Sutrop, Urmas. 2001. "List Tasks and a Cognitive Salience Index”. Field Methods 13(3):263276.

Weller, Susan C. 2014. "Structured Interviewing and Questionnaire Construction.” In Hanbook of Methods in Cultural Anthropology, Second Edition. Eds. H. Russell Bernard and Clarence C. Gravlee. Pp. 343-390. Plymouth, UK: Rowman \& Littlefield.

Weller, Susan C. and A. Kimball Romney. 1988. Systematic Data Collection. London: Sage. 
Meaning in the Miscellany of a Cultural Domain

\section{Daniel Souleles}

Figure captions:

Figure 3 common items, X Y with PROFIT line.

Figure 4 common items, Y Z with PROFIT line.

Figure 5 singleton items, X Y with PROFIT line. Figure 6 singleton items, Y Z with PROFIT line. 


\begin{tabular}{|l|l|}
\hline Item & Frequency \\
\hline Party & 28 \\
\hline Drink & 25 \\
\hline Shop & 24 \\
\hline Movies & 23 \\
\hline Netflix & 18 \\
\hline Out to eat & 16 \\
\hline TV & 16 \\
\hline Play Sports & 15 \\
\hline Sleep & 15 \\
\hline Hangout & 15 \\
\hline Into City & 14 \\
\hline Music & 14 \\
\hline Eat & 13 \\
\hline Videogames & 13 \\
\hline Cook & 13 \\
\hline Weed & 13 \\
\hline Concert & 12 \\
\hline Read & 11 \\
\hline Travel & 10 \\
\hline Sex & 9 \\
\hline Drugs & 9 \\
\hline Youtube & 7 \\
\hline Exercise & 7 \\
\hline Sporting Events & 7 \\
\hline Dance & 7 \\
\hline Board Game & 7 \\
\hline Draw & 7 \\
\hline Out to Movie & 7 \\
\hline Talk with Friends & 7 \\
\hline Hookup & 7 \\
\hline Social Media & $8 *$ \\
\hline Pranks & 1 \\
\hline & \\
\hline
\end{tabular}

*Combined Facebook (3) with Social Media (5).

\begin{tabular}{|c|c|}
\hline Item & Frequency \\
\hline Pranks & 1 \\
\hline Eat Candy & 1 \\
\hline Walks with Friends & 1 \\
\hline Improv & 1 \\
\hline $\mathrm{HBO}$ & 1 \\
\hline Frat Parties & 1 \\
\hline Adventures & 1 \\
\hline Sight See & 1 \\
\hline Read Books & 1 \\
\hline Bike Ride & 1 \\
\hline Catch Up With Friends & 1 \\
\hline Majang [sic] & 1 \\
\hline Procrastinate on Phone & 1 \\
\hline Beer Pong & 1 \\
\hline Amazon & 1 \\
\hline Direct Movies & 1 \\
\hline Make Memes & 1 \\
\hline Comedy Shows & 1 \\
\hline Play with Phone & 1 \\
\hline Meet New People & 1 \\
\hline People Watch & 1 \\
\hline Couch Surf & 1 \\
\hline Grocery Store & 1 \\
\hline Dinner With Friends & 1 \\
\hline Forget About Assignments & 1 \\
\hline Live & 1 \\
\hline Family Reunion & 1 \\
\hline Go to NYC & 1 \\
\hline Got to Montreal & 1 \\
\hline $\begin{array}{l}\text { Learn about People's } \\
\text { Families }\end{array}$ & 1 \\
\hline Kickback & 1 \\
\hline Chill & 1 \\
\hline Events & 1 \\
\hline Orientation Leader & 1 \\
\hline Window Shop & 1 \\
\hline Chat & 1 \\
\hline Take a Break & 1 \\
\hline Stare Into Space & 1 \\
\hline Facebook Stalk & 1 \\
\hline Free Time & 1 \\
\hline Cosplay & 1 \\
\hline Yik Yak & 1 \\
\hline Sew & 1 \\
\hline Cut Wood & 1 \\
\hline Box & 1 \\
\hline Shower & 1 \\
\hline Games & 1 \\
\hline Text & 1 \\
\hline Selfies & 1 \\
\hline Tinder & 1 \\
\hline
\end{tabular}

Figures 1, 2 Common (L), Singleton (R) List Items 


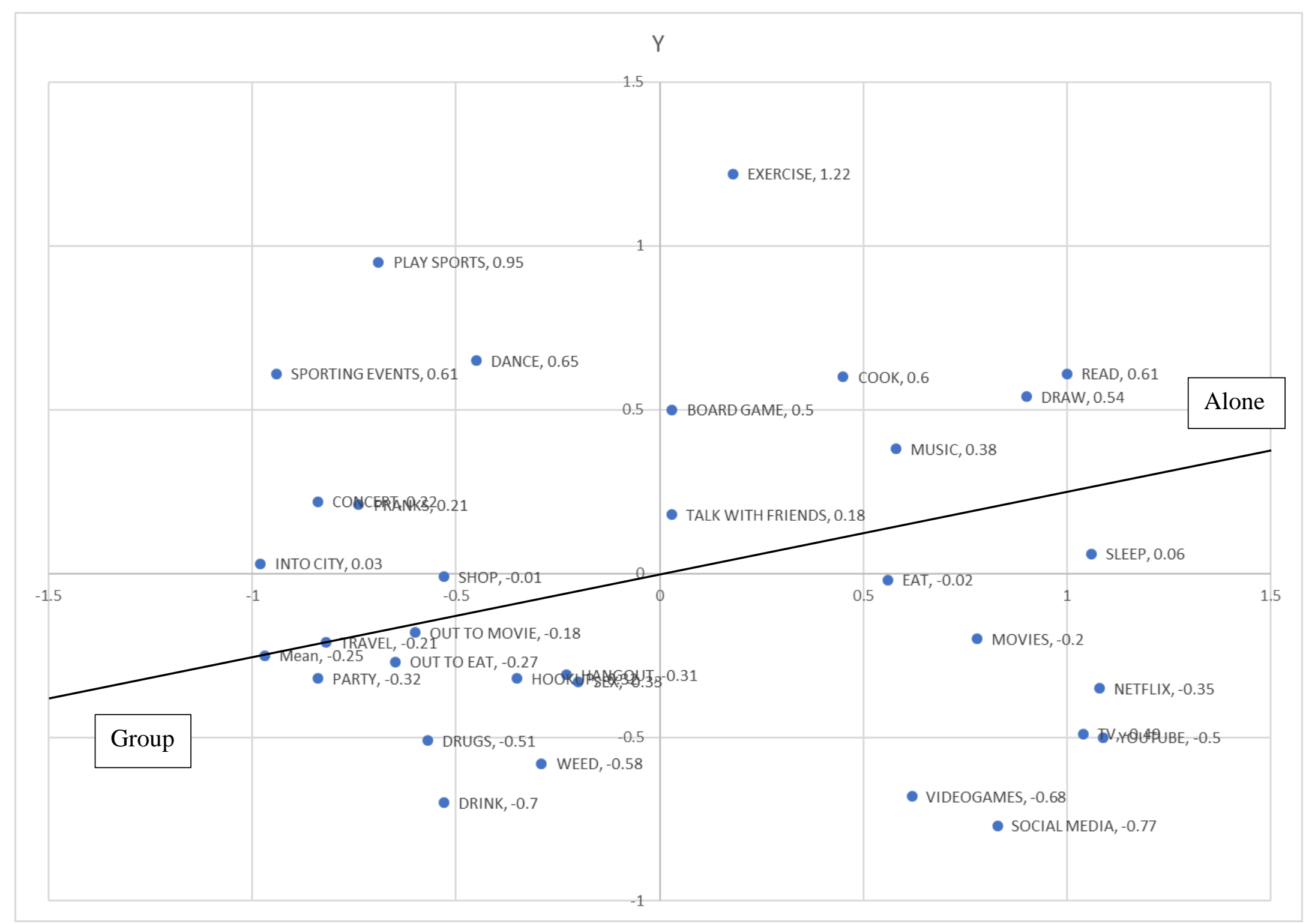

Figure 3 plot of Common items, $X Y$ with PROFIT line. 


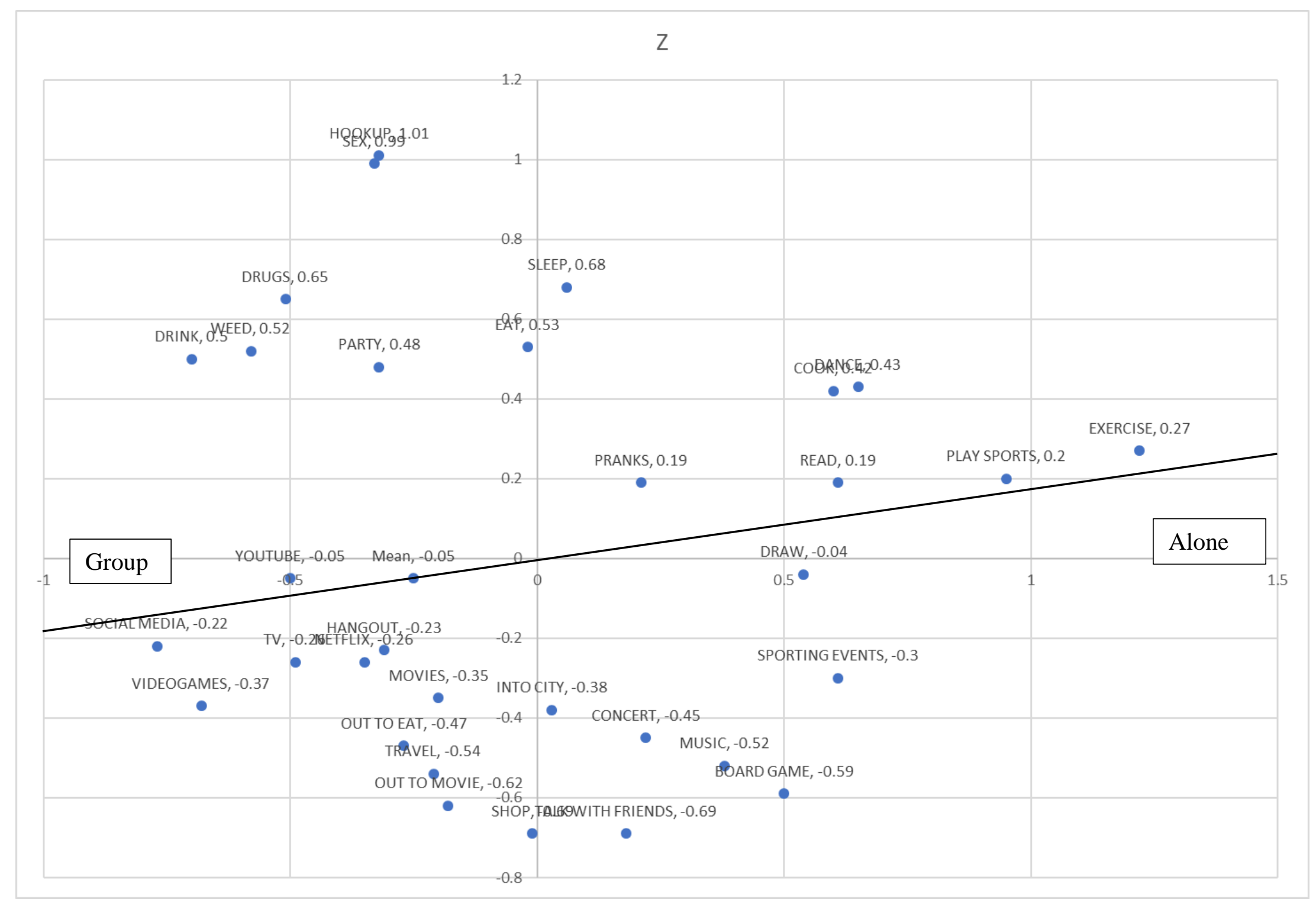

Figure 4 plot of Common items, $Y Z$ with PROFIT line. 


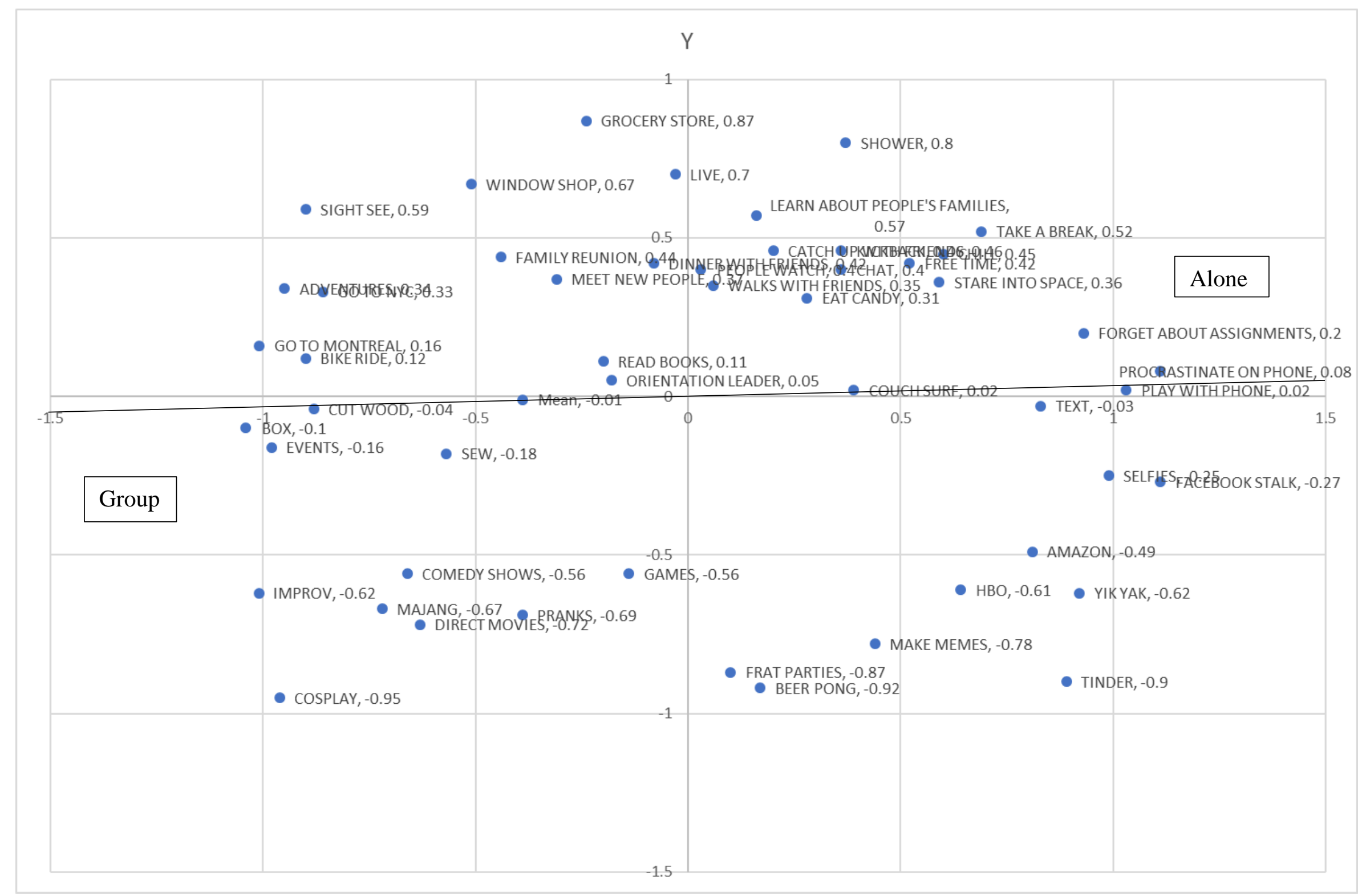

Figure 5 plot of singleton items, X Y PROFIT line. 
Z

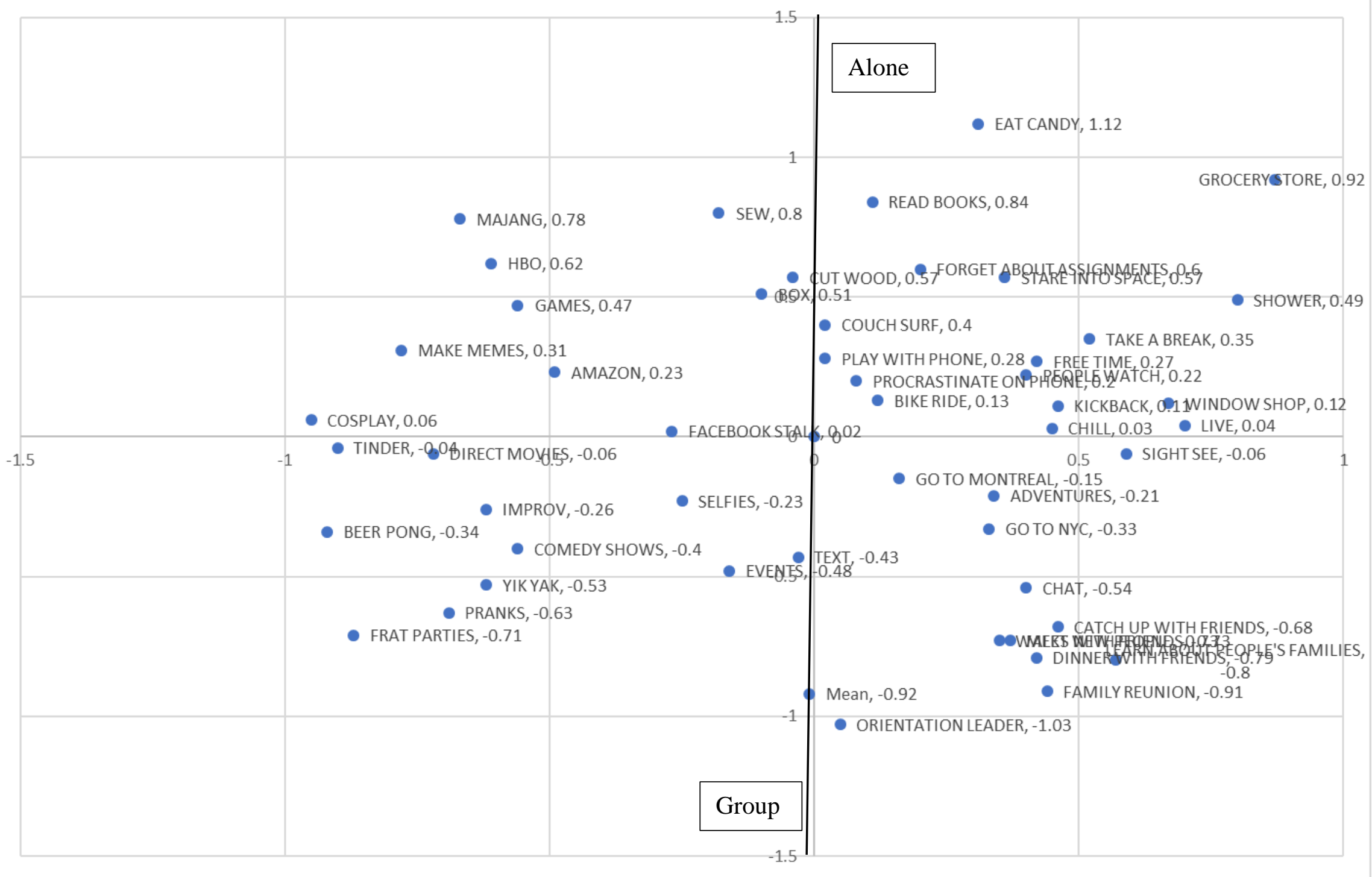

Figure 6 plot of singleton items, Y Z plot with PROFIT line. 